\title{
PRODUÇÃO DE EXOPOLISSACARÍDEOS BACTERIANOS EM DIFERENTES FONTES DE CARBONO
}

\author{
R. A. TRINDADE ${ }^{1}$, A. P. MUNHOZ ${ }^{1}$ e C. A. V. BURKERT ${ }^{1}$ \\ ${ }^{1}$ Universidade Federal do Rio Grande, Escola de Química e Alimentos \\ E-mail para contato: rtrindade@furg.br
}

\begin{abstract}
RESUMO - O objetivo do trabalho foi testar a sacarose (S), mistura de sacarose e glicerol residual (SGR) $(1: 1 \mathrm{~m} / \mathrm{m})$ e glicerol residual (GR) como fonte de carbono na produção de diferentes exopolissacarídeos (EPSs) bacterianos. Os cultivos foram realizados em frascos agitados $\left(28^{\circ} \mathrm{C} / 200 \mathrm{rpm}\right)$. A bactéria Xanthomonas campestris apresentou concentração de EPSs em GR igual ou superior aos valores encontrados com S, de aproximadamente 4 g.L. ${ }^{-1}$. Pseudomonas oleovorans apresentou concentração também em torno de 4 g.L $\mathrm{L}^{-1} \mathrm{em}$ SGR e GR, sendo a concentração encontrada em $\mathrm{S}\left(0,8 \mathrm{~g} . \mathrm{L}^{-1}\right)$ inferior aos demais. Sphingomonas capsulata apresentou uma maior concentração em S e SGR em torno de 3,4 g. $\mathrm{L}^{-1}$, sendo que em GR este valor caiu para 1,7 g.L $\mathrm{L}^{-1}$. Já Zymomonas mobilis apresentou um melhor resultado em meio SGR (1,3 g.L $\left.\mathrm{L}^{-1}\right)$, sendo que em $\mathrm{S}$ e GR estes valores caíram para 0,2 e 0,7 g. $\mathrm{L}^{-1}$, respectivamente. Desta forma, pode-se concluir que a glicerina residual pode ser considerada uma alternativa em substituição à sacarose na produção de EPSs bacterianos.
\end{abstract}

\section{INTRODUÇÃO}

O petróleo é a principal fonte de energia no mundo, mas por se tratar de um combustível de origem fóssil, e com expectativa de diminuição das suas reservas no futuro próximo, pesquisas vêm sendo realizadas com o objetivo de desenvolver fontes de energia renováveis (Silva et al., 2009). Uma alternativa é a utilização de biocombustíveis, como por exemplo, o biodiesel (Mota et al., 2009), cujo processo de produção gera cerca de 10\% de glicerol (Abad; Turon, 2012). Os biocombustíveis podem ser definidos como combustíveis produzidos a partir de biomassas agrícolas, portanto renováveis, pois reduzem a emissão de gases de efeito estufa em função da absorção do gás carbônico atmosférico que ocorre na produção da biomassa (Bonomi et al., 2006).

Por outro lado, um alto potencial de aplicação nos mais diversos segmentos industriais tem surgido para biopolímeros microbianos, também chamados de exopolissacarídeos (EPSs), os quais são secretados pelas células, sendo produzidos por diferentes bactérias e usados em produtos alimentícios, farmacêuticos, químicos, entre outros (Luvielmo; Scamparini, 2009; Freitas et al., 2011; Prasanna et al., 2012). Os açúcares constituem as fontes de carbono mais comumente utilizadas para a produção de EPSs bacterianos. No entanto, substratos de baixo custo, tais como resíduos industriais, têm demonstrado serem adequados para a produção desses EPSs (Freitas et al., 2011). Sendo assim, torna-se importante investigar o uso do glicerol residual como fonte de carbono em cultivos para produção de EPSs, de forma a permitir o aproveitamento do excedente gerado na produção do biodiesel, contribuindo assim para o desenvolvimento sustentável da cadeia produtiva do biodiesel, 
além de diminuir custos do processo por aproveitar um coproduto de baixo custo e grande disponibilidade.

O presente trabalho propõe verificar a possibilidade de substituir total ou parcialmente a sacarose utilizada na produção de diferentes EPSs bacterianos, por glicerol residual.

\section{MATERIAL E MÉTODOS}

\subsection{Micro-organismo}

A bactéria Xanthomonas campestris pv. mangiferaeindicae IBSBF 1230 foi obtida da Coleção de Culturas de Fitobactérias do Instituto Biológico (IBSBF) - Campinas - SP, Brasil. As demais bactérias, Pseudomonas oleovorans NRRL B-14683, Sphingomonas capsulata NRRL B-4261 e Zymomonas mobilis subspecies mobilis NRRL B-4286, foram obtidas da ARS Culture Collection, Bacterial Foodborne Pathogens and Mycology Research Unit - National Center for Agricultural Utilization Research - Peoria, Estados Unidos.

\subsection{Glicerol Residual}

O glicerol residual proveniente da obtenção de biodiesel a partir do óleo de soja por via metanólica foi fornecido pela empresa BS Bios Indústria e Comércio de Biodiesel Sul Brasil S/A (Passo Fundo - RS). O glicerol residual continha $81,92 \%(\mathrm{~m} / \mathrm{m})$ de pureza, de acordo com laudo fornecido pela própria empresa, sendo que a quantidade adicionada nos meios levou em conta sua composição, a fim de resultar na concentração desejada do substrato (glicerol) nos meios de cultivo.

\subsection{Re-hidratação das Culturas Liofilizadas}

As culturas acondicionadas em ampolas de vidro foram rompidas em condições estéreis. $\mathrm{Na}$ ampola que continha a bactéria Xanthomonas campestris pv. mangiferaeindicae IBSBF 1230 foram adicionadas 5 gotas do Caldo Nutriente, sendo após incubada a $28^{\circ} \mathrm{C}$ durante $60 \mathrm{~min}$. Transcorrido esse tempo, a suspensão foi transferida para placas de Petri contendo Ágar Nutriente ( 5 g.L $\mathrm{L}^{-1}$ peptona; 6 g.L $\mathrm{L}^{-1} \mathrm{NaCl} ; 1,5$ g.L $\mathrm{L}^{-1}$ extrato de carne; 1,5 g.L $\mathrm{L}^{-1}$ extrato de levedura; 15 g.L $\mathrm{L}^{-1}$ ágar) e incubadas a $28^{\circ} \mathrm{C}$ por $48 \mathrm{~h}$ (IBSBF, 2013). Para as bactérias Pseudomonas oleovorans NRRL B-14683 e Sphingomonas capsulata NRRL B-4261 foi realizado o mesmo procedimento, sendo utilizado o meio TGY (5 g.L $\mathrm{L}^{-1}$ triptona; 5 g.L $\mathrm{L}^{-1}$ extrato de levedura; 1 g.L ${ }^{-1}$ glicose; 1 g.L $\mathrm{L}^{-1} \mathrm{~K}_{2} \mathrm{HPO}_{4} ; 10$ g.L $\mathrm{L}^{-1}$ ágar). Já para a bactéria Zymomonas mobilis NRRL B-4286 o meio utilizado para a reativação foi o YP (20 g.L $\mathrm{L}^{-1}$ peptona; 10 g.. $\mathrm{L}^{-1}$ extrato de levedura; 20 g.L $\mathrm{L}^{-1}$ glicose; 20 g. $\mathrm{L}^{-1}$ ágar).

\subsection{Manutenção das Culturas Microbianas}

A partir das culturas re-hidratadas foram realizados repiques sucessivos, sendo utilizado para Xanthomonas campestris pv. mangiferaeindicae 1230 o meio YM (3 g. $\mathrm{L}^{-1}$ extrato de levedura; 3 g.L $\mathrm{L}^{-1}$ extrato de malte; 5 g.L . $^{-1}$ peptona; 20 g.L $L^{-1}$ glicose; 10 g.L $L^{-1}$ ágar), pH 7,2 (MESOMO, 2007). Para as bactérias Pseudomonas oleovorans NRRL B-14683 e Sphingomonas 


\section{9 a 22 de outubro de 2014 \\ Florianópolis/SC}

capsulata NRRL B-4261 foi utilizado o meio contendo: 20 g.L $\mathrm{L}^{-1}$ glicose; 5 g.L ${ }^{-1}$ peptona; 3 g.L ${ }^{-1}$ extrato de levedura; 5 g.L $\mathrm{L}^{-1}$ cloreto de sódio; 20 g.L $\mathrm{L}^{-1}$ ágar; água destilada q.s.p., pH 6,8-7,0 (Bajaj et al., 2006). Já para a bactéria Zymomonas mobilis NRRL B-4286 o meio utilizado continha: 20 g.L $\mathrm{L}^{-1}$ sacarose; 2,5 g. $\mathrm{L}^{-1}$ extrato de levedura; 1 g.L $\mathrm{L}^{-1} \mathrm{KH}_{2} \mathrm{PO}_{4} ; 1$ g.L $\mathrm{L}^{-1}\left(\mathrm{NH}_{4}\right)_{2} \mathrm{SO}_{4} ; 0,5$ g.L ${ }^{-1}$ $\mathrm{MgSO}_{4} .\left(7 \mathrm{H}_{2} \mathrm{O}\right) ; 20$ g.L $\mathrm{L}^{-1}$ ágar (Oliveira et al., 2007).

Todas as bactérias foram incubadas para crescimento celular em estufa com temperatura controlada $\left(28^{\circ} \mathrm{C}\right)$ por $48 \mathrm{~h}$. As cepas foram mantidas refrigeradas, sendo realizados repiques mensais.

\subsection{Preparo do Inóculo}

O inóculo foi preparado partindo de um tubo contendo a cultura microbiana reativada, sendo raspada com $10 \mathrm{~mL}$ de água peptonada $0,1 \%$, a fim de resultar em uma suspensão de células. Esta foi transferida para $90 \mathrm{~mL}$ de meio apropriado contido em frasco Erlenmeyer de 500 $\mathrm{mL}$. Os frascos foram mantidos em incubadora refrigerada com agitação orbital (Tecnal TE 424, Brasil) a $28{ }^{\circ} \mathrm{C}$ e $150 \mathrm{rpm}$, até atingir uma densidade ótica (DO $560 \mathrm{~nm}$ ) estabelecida (1,9 $2,1)$.

\subsection{Cultivos em Frascos Agitados}

Foram realizados cultivos em frascos Erlenmeyer de $500 \mathrm{~mL}$. Suspensão microbiana correspondente a $10 \%$ do volume total $(10 \mathrm{~mL})$, foi transferida para $90 \mathrm{~mL}$ de meio de cultivo, a fim de totalizar $100 \mathrm{~mL}$ de meio. Os frascos foram mantidos em incubadora refrigerada com agitação orbital (Tecnal TE-424, Brasil), na temperatura de $28^{\circ} \mathrm{C}$ e $200 \mathrm{rpm}$ de agitação.

Nesta etapa, foram utilizados meios de produção específicos para cada micro-organismo, conforme descrito na Tabela 1. Como fontes de carbono foram testadas a sacarose (S), o glicerol residual (GR), considerando sua composição a fim de resultar na concentração desejada do substrato, e uma mistura de ambos na proporção de $1: 1(\mathrm{~m} / \mathrm{m})$, totalizando a concentração indicada (SGR), como sugerido por Reis et al. (2010), já que a sacarose é a fonte de carbono usual na produção dos EPSs estudados.

Para determinação dos EPSs, os cultivos foram conduzidos por $48 \mathrm{~h}$, sendo que todo o conteúdo dos frascos $(100 \mathrm{~mL})$ foi centrifugado sob refrigeração, para determinações analíticas no sobrenadante (concentrações de EPSs) e no sedimento (biomassa), conforme métodos descritos no item 2.7. Todos os cultivos foram realizados em triplicata. Os resultados foram analisados por análise de variância e teste de Tukey (Montgomery, 2004), a fim de verificar a existência de diferenças significativas entre os meios estudados para um mesmo microorganismo, a 95\% de confiança $(\mathrm{p} \leq 0,05)$. 


\section{9 a 22 de outubro de 2014 \\ Florianópolis/SC}

Tabela 1 - Composição dos meios de produção de EPSs

\begin{tabular}{|c|c|c|}
\hline Micro-organismo & Composição do meio (g.L $\left.{ }^{-1}\right)^{*}$ & Referência \\
\hline $\begin{array}{c}\text { Xanthomonas } \\
\text { campestris }\end{array}$ & $\begin{array}{l}50 \text { fonte de carbono; } 2,5 \mathrm{NH}_{4} \mathrm{H}_{2} \mathrm{PO}_{4} ; 5,0 \\
\mathrm{~K}_{2} \mathrm{HPO}_{4} ; 0,006 \mathrm{H}_{3} \mathrm{BO}_{3} ; 2\left(\mathrm{NH}_{4}\right)_{2} \mathrm{SO}_{4} ; 0,0024 \\
\mathrm{FeCl}_{3} ; 0,002 \mathrm{CaCl}_{2} .2 \mathrm{H}_{2} \mathrm{O} ; 0,002 \mathrm{ZnSO}_{4} ; \mathrm{pH} \mathrm{7,0.}\end{array}$ & Reis et al. (2010) \\
\hline $\begin{array}{c}\text { Pseudomonas } \\
\text { oleovorans }\end{array}$ & $\begin{array}{c}25 \text { fonte de carbono; } 3,3\left(\mathrm{NH}_{4}\right)_{2} \mathrm{HPO}_{4} ; 5,8 \\
\mathrm{~K}_{2} \mathrm{HPO}_{4} ; 3,7 \mathrm{KH}_{2} \mathrm{PO}_{4} ; 10 \mathrm{~mL} \text { de solução de } \\
\mathrm{MgSO}_{4} 100 \mathrm{mM} ; 1 \mathrm{~mL} \text { de solução de } \\
\text { micronutrientes**; } \mathrm{pH} 7,0 .\end{array}$ & $\begin{array}{l}\text { Freitas et al. } \\
\qquad(2010)\end{array}$ \\
\hline $\begin{array}{l}\text { Sphingomonas } \\
\text { capsulata }\end{array}$ & $\begin{array}{c}20 \text { fonte de carbono; } 10 \mathrm{Na}_{2} \mathrm{HPO}_{4} ; 1 \mathrm{~K}_{2} \mathrm{SO}_{4} ; 1 \\
\mathrm{NaCl} ; 0,15\left(\mathrm{NH}_{4}\right)_{2} \mathrm{SO}_{4} ; 0,2 \mathrm{MgSO}_{4} \cdot 7 \mathrm{H}_{2} \mathrm{O} ; 0,01 \\
\mathrm{CaCl}_{2} .2 \mathrm{H}_{2} \mathrm{O} ; 0,001 \mathrm{FeSO}_{4} .7 \mathrm{H}_{2} \mathrm{O} ; 0,5 \text { extrato de } \\
\text { levedura; } \mathrm{pH} 6,8-7,0 .\end{array}$ & $\begin{array}{l}\text { Bajaj et al. } \\
\text { (2006) }\end{array}$ \\
\hline $\begin{array}{l}\text { Zymomonas } \\
\text { mobilis }\end{array}$ & $\begin{array}{l}20 \text { fonte de carbono; } 2,5 \text { extrato de levedura; } 1 \\
\mathrm{KH}_{2} \mathrm{PO}_{4} ; 1\left(\mathrm{NH}_{4}\right)_{2} \mathrm{SO}_{4} ; 0,5 \mathrm{MgSO}_{4} \cdot 7 \mathrm{H}_{2} \mathrm{O} ; \mathrm{pH} \\
7,0 \text {. }\end{array}$ & $\begin{array}{l}\text { Oliveira et al. } \\
\quad(2007)\end{array}$ \\
\hline
\end{tabular}

* Como fontes de carbono foram usadas sacarose, glicerina residual e a mistura de ambos na mesma proporção mássica (1:1), resultando na concentração indicada.

**Solução de micronutrientes (em g.L ${ }^{-1}$ de $\mathrm{HCl} 1 \mathrm{~N}$ ): $2,78 \mathrm{FeSO}_{4} \cdot 7 \mathrm{H}_{2} \mathrm{O} ; 1,98 \mathrm{MnCl}_{2} \cdot 4 \mathrm{H}_{2} \mathrm{O} ; 2,81$ $\mathrm{CoSO}_{4} \cdot 7 \mathrm{H}_{2} \mathrm{O} ; 1,67 \mathrm{CaCl}_{2} \cdot 2 \mathrm{H}_{2} \mathrm{O} ; 0,17 \mathrm{CuCl}_{2} \cdot 2 \mathrm{H}_{2} \mathrm{O} ; 0,29 \mathrm{ZnSO}_{4} \cdot 7 \mathrm{H}_{2} \mathrm{O}$.

\subsection{Determinação da Biomassa e Concentração dos EPSs}

A recuperação dos EPSs do meio de cultivo foi realizada através da centrifugação do meio a 3400 g por 30 min a $4^{\circ} \mathrm{C}$, para remoção de células, seguido de precipitação do EPS pela adição de etanol $96,4^{\circ} \mathrm{GL}(1: 4 \mathrm{v} / \mathrm{v})$, repouso por $24 \mathrm{~h}$ a $4^{\circ} \mathrm{C}$, sendo novamente centrifugado por $30 \mathrm{~min}$, sob refrigeração $\left(4^{\circ} \mathrm{C}\right)$. A concentração dos EPSs foi determinada por gravimetria, secando em estufa a $50^{\circ} \mathrm{C}$ até peso constante, relacionando ao volume de amostra (Mesomo, 2007).

O crescimento celular foi monitorado por medida da absorvância a $560 \mathrm{~nm}$, baseado no procedimento descrito por Prieto et al. (2008). A concentração de biomassa foi expressa em peso seco (g.L $\mathrm{L}^{-1}$ ), obtido a partir de uma curva de calibração previamente determinada para cada micro-organismo.

\section{RESULTADOS E DISCUSSÃO}

\subsection{Biomassa e EPS Utilizando Diferentes Fontes de Carbono}

A Tabela 2 apresenta os resultados referentes à produção de EPSs e biomassa em $48 \mathrm{~h}$ pelas bactérias X. campestris pv. mangiferaeindicae IBSBF 1230, Pseudomonas oleovorans NRRL B14683, Sphingomonas capsulata NRRL B-4261 e Zymomonas mobilis NRRL B-4286. 
Tabela 2 - Resultados da produção de EPS e biomassa em $48 \mathrm{~h}$ de cultivo.

\begin{tabular}{|c|c|c|c|c|}
\hline \multicolumn{5}{|c|}{ EPS (g.L $\left.{ }^{-1}\right)$} \\
\hline & X. campestris & P. oleovorans & S. capsulata & Z. mobilis \\
\hline $\mathrm{S}$ & $4,55 \pm 0,37^{\text {a,b }}$ & $0,84 \pm 0,05^{b}$ & $3,44 \pm 0,22^{a}$ & $0,27 \pm 0,03^{c}$ \\
\hline SGR & $4,07 \pm 0,14^{\mathrm{b}}$ & $4,11 \pm 0,13^{a}$ & $3,51 \pm 0,14^{\mathrm{a}}$ & $1,42 \pm 0,16^{\mathrm{a}}$ \\
\hline GR & $4,98 \pm 0,36^{\mathrm{a}}$ & $3,99 \pm 0,20^{\mathrm{a}}$ & $1,87 \pm 0,19^{b}$ & $0,77 \pm 0,09^{b}$ \\
\hline \multicolumn{5}{|c|}{ Biomassa $\left(\mathrm{g} . \mathrm{L}^{-1}\right)$} \\
\hline $\mathrm{S}$ & $0,15 \pm 0,01^{b}$ & $4,06 \pm 0,04^{b}$ & $0,87 \pm 0,05^{\mathrm{a}}$ & $0,83 \pm 0,02^{\mathrm{a}}$ \\
\hline SGR & $0,19 \pm 0,01^{a}$ & $3,99 \pm 0,05^{b}$ & $0,86 \pm 0,01^{a}$ & $0,68 \pm 0,01$ \\
\hline GR & $0,16 \pm 0,01^{b}$ & $4,30 \pm 0,04^{\mathrm{a}}$ & $0,86 \pm 0,02^{a}$ & $0,22 \pm 0,01^{c}$ \\
\hline
\end{tabular}

*Letras minúsculas diferentes indicam que há diferença significativa para as duas respostas $(\mathrm{p}<0,05)$.

Pode-se observar que foi encontrada uma produção de EPS de 4,98 g.L ${ }^{-1}$ para a bactéria $X$. campestris quando GR foi utilizado como fonte de carbono, não diferindo significativamente do EPS produzido com S (4,55 g. $\left.\mathrm{L}^{-1}\right)$. Ainda, o meio contendo somente $\mathrm{S}$ não diferiu significativamente do meio contendo SGR (4,07 g.L.-1). A maior concentração de biomassa foi encontrada com SGR $\left(0,19\right.$ g. $\left.\mathrm{L}^{-1}\right)$, diferindo significativamente $(\mathrm{p}<0,05)$ das demais fontes de carbono. Moreira et al. (2001) avaliaram a produção da goma xantana por dezoito cepas da bactéria $X$. campestris pv pruni, utilizando a sacarose como fonte de carbono, sendo incubadas a $28^{\circ} \mathrm{C}$ e $200 \mathrm{rpm}$ de agitação, obtendo concentrações da goma variando de 2,3 até 8,3 g.L $\mathrm{L}^{-1}$ após $72 \mathrm{~h}$ de cultivo.

Para a bactéria $P$. oleovorans pode-se perceber que foi encontrada uma maior concentração de EPSs com SGR (4,11 g.L $\left.\mathrm{L}^{-1}\right)$ e GR $\left(3,99\right.$ g.L $\left.\mathrm{L}^{-1}\right)$, que não diferiram significativamente entre si. A concentração de EPSs em meio com $S$ foi bastante inferior, diferindo significativamente das demais. Já a concentração de biomassa foi maior em meio com GR (4,30 g.L $\left.{ }^{-1}\right)$, diferindo significativamente dos demais meios. Hiliou et al. (2009), utilizando a mesma cepa, como fonte de carbono o glicerol $\left(25 \mathrm{~g} . \mathrm{L}^{-1}\right)$ e como fonte de nitrogênio o $\left(\mathrm{NH}_{4}\right)_{2} \mathrm{HPO}_{4}\left(3,3 \mathrm{~g} . \mathrm{L}^{-1}\right)$, obtiveram 13,3 g. $\mathrm{L}^{-1}$ de EPSs, sendo o pH 6,75-6,85 e a aeração 0,125 vvm. Este valor foi encontrado em sete dias de cultivo, utilizando biorreator de $10 \mathrm{~L}$, onde as condições de aeração e agitação são muito mais eficientes.

Pode-se perceber que a maior concentração de EPS para a bactéria $S$. capsulata foi de 3,44 g. $\mathrm{L}^{-1}$ e 3,51 g.L $\mathrm{L}^{-1}$, quando utilizadas a $\mathrm{S}$ e GR como fonte de carbono, não diferindo entre si, sendo a concentração encontrada, quando utilizado o GR como fonte de carbono, bastante inferior $\left(1,87\right.$ g.L $\left.{ }^{-1}\right)$. As concentrações de biomassa para as três fontes de carbono não diferiram significativamente, ficando em torno de $0,90 \mathrm{~g} . \mathrm{L}^{-1}$. Bajaj et al. (2006) encontraram para bactéria S. paucimobilis em meio contendo $\mathrm{S}$ como fonte de carbono uma concentração de biomassa em torno de 0,25 g. $\mathrm{L}^{-1}$, sendo a maior concentração de biomassa encontrada quando amido solúvel foi utilizado como fonte de carbono $\left(0,46 \mathrm{~g} \cdot \mathrm{L}^{-1}\right)$.

Para a bactéria $Z$. mobilis pode-se perceber que houve uma maior concentração de EPSs em meio contendo a mistura SGR (1,42 g.L $\left.{ }^{-1}\right)$, seguido pelo GR $\left(0,77\right.$ g.L $\left.{ }^{-1}\right)$ e S $\left(0,27\right.$ g.L - $\left.^{-1}\right)$. A concentração de biomassa foi maior em meio com S $\left(0,83\right.$ g.L $\left.\mathrm{L}^{-1}\right)$, seguido por SGR $\left(0,68\right.$ g.L $\left.\mathrm{L}^{-1}\right)$ e 
GR (0,22 g.L $\left.{ }^{-1}\right)$. Oliveira et al. (2007), utilizando 250 g. $\mathrm{L}^{-1}$ de sacarose (fonte de carbono), em 24 $\mathrm{h}$ de cultivo, encontraram uma concentração de biomassa de 0,85 g. $\mathrm{L}^{-1}$, resultado similar ao encontrado neste trabalho $\left(0,83 \mathrm{~g} . \mathrm{L}^{-1}\right)$ quando $\mathrm{S}$ foi usada.

\section{CONCLUSÃO}

Ao comparar as bactérias $X$. campestris pv. mangiferaeindicae IBSBF 1230, P. oleovorans NRRL B-14683, S. capsulata NRRL B-4261 e Z. mobilis NRRL B-4286, todas foram capazes crescer e produzir EPSs em meio contendo somente GR como fonte de carbono, em $48 \mathrm{~h}$ de cultivo, sendo que as bactérias $X$. campestris e $P$. oleovorans foram capazes de produzir iguais ou maiores concentrações de EPSs quando utilizado somente GR como fonte de carbono em relação às demais fontes, não havendo uma relação definida entre concentração de biomassa e produção de EPSs. Desta forma, foi demonstrado que o GR pode ser uma boa alternativa de fonte de carbono, em substituição à sacarose, no cultivo de algumas bactérias produtoras de EPSs.

\section{AGRADECIMENTOS} de bolsa.

Os autores agradecem à FAPERGS e CNPq pelo apoio financeiro, e à CAPES pela concessão

\section{REFERÊNCIAS BIBLIOGRÁFICAS}

ABAD, S.; TURON, X. Valorization of biodiesel derived glycerol as a carbon source to obtain added-value metabolites: Focus on polyunsaturated fatty acids. Biotechnol. Adv., v. 30, p. 733$740,2012$.

BAJAJ, I. B.; SAUDAGAR, P.S.; SINGHAL, R.S.; PANDEY, A. Statistical approach to optimization of fermentative production of gellan gum from Sphingomonas paucimobilis ATCC 31461. J. Biosci. Bioeng., v. 102, n. 3, p. 150-156, 2006.

BONOMI, A.; POÇO, J.G.; TRIELLI, M.A. Biocombustíveis - a solução brasileira para uma matriz energética sustentável. Rev. Bras. Eng. Quím., v. 22, p. 16-21, 2006.

FREITAS, F.; ALVES, V.D.; PAIS, J.; CARVALHEIRA, M.; COSTA, N.; OLIVEIRA, R.; REIS, M.A.M. Production of a new exopolysaccharide (EPS) by Pseudomonas oleovorans NRRL B-14682 grown on glycerol. Process. Biochem., v. 45, p. 297-305, 2010.

FREITAS, F.; ALVES, V.D.; REIS, M.A.M. Advances in bacterial exopolysaccharides: from production to biotechnological applications. Trends Biotechnol., v. 29, p. 388-398, 2011.

HILLIOU, L.; FREITAS, F.; OLIVEIRA, R.; REIS, M.A.M.; LESPINEUX, D.; GRANDFILS, C.; ALVES, V.D. Solution properties of an exopolysaccharide from a Pseudomonas strain obtained using glycerol as sole carbon source. Carbohyd. Polym., v. 78, p. 526-532, 2009. 
IBSBF - Coleção de Cultura de Fitobactérias do Instituto Biológico. Instruções para rehidratação das culturas. Campinas, São Paulo, 2013.

LUVIELMO, M.M.; SCAMPARINI, A.R.P. Goma xantana: produção, recuperação, propriedades e aplicação. Estudos Tecnológicos, v. 5, p. 50-67, 2009.

MESOMO, M.C. Produção de goma xantana em biorreator utilizando meio à base de soro de queijo. 2007. 81 f. Dissertação (Mestrado em Engenharia de Alimentos) - Universidade do Alto Uruguai e das Missões (URI), Erechim.

MONTGOMERY, D.C. Introdução ao controle estatístico de qualidade. $4^{\circ}$ Edição. Rio de Janeiro: Editora LTC, 2004.

MOREIRA, A.S.; VENDRUSCOLO, J.L.S.; GIL-TURNES, C.; VENDRUSCOLO, C.T. Screening among 18 novel strains of Xanthomonas campestris pv pruni. Food Hydroccolloid., v. 15, p. 469-474, 2001.

MOTA, C.J.; SILVA, C.X.A.; GONÇALVES, V.L.C. Gliceroquímica: novos produtos e processos a partir da glicerina de produção de biodiesel. Quim. Nova, v. 32, n. 3, p. 639-648, 2009.

OLIVEIRA, M.R.; SILVA, R.S.S.F.; BUZATO, J.B.; CELLIGOI, M.A.P.C. Study of levan production by Zymomonas mobilis using regional low-cost carbohydrate sources. Biochem. Eng. J., v. 37, p. 177-183, 2007.

PRASANNA,P.H.P.; BELL, A.; GRANDISON, A.S.; CHARALAMPOPOULOS, D. Emulsifying, rheological and physicochemical properties of exopolysaccharide produced by Bifidobacterium longum subsp. Infantis CCUG 52486 and Bifidobacterium infantis NCIMB 702205. Carbohyd. Polym., v. 90, p. 533-540, 2012.

PRIETO, L. M.; MICHELON, M.; BURKERT, J.F.M.; KALIL, S.J.; BURKERT, C.A.V. The production of rhamnolipid by a Pseudomonas aeruginosa strain isolated from a southern coastal zone in Brazil. Chemosphere, v. 71, p. 1781-1785, 2008.

REIS, E.C.; ALMEIDA, M.; CARDOSO, J.C.; PEREIRA, M.A.; OLIVEIRA, C.B.Z.; VENCESCAU, E.M.; DRUZIAN, J.I.; MARIANO, R.; PADILHA, F.F. Biopolymer synthesized by strains of Xanthomonas sp isolate from Brazil using biodiesel-waste. Macromol. Symp., v. 296, p. 347-353, 2010.

SILVA, G. P.; MACK, M.; CONTIERO, J. Glycerol: a promising and abundant carbon source for industrial microbiology. Biotechnol. Adv., v. 27, p. 30-39, 2009. 